\title{
Using big data at Istat: forecasting consumption
}

\author{
Bacchini, Fabio; Iannaccone, Roberto and Zurlo, Davide
}

Istat, Econometric Studies and Economic Forecasting Division, Rome, Italy

\begin{abstract}
In our paper we discuss the possibility to use Big Data on payment instruments to improve the short-term forecast of Italian household consumption.
\end{abstract}

The literature on forecasting has evolved rapidly in the last few years. Several papers have been focused on the use of variable selection methods on large dataset of economic indicators that can potentially improve the forecasting of the main macroeconomic variables. The variable selection methods implemented anyway are always based on economic indicator (soft or hard) released by the Statistical Offices.

More recently given the presence of several sources of data on real-time economic activity available from Google, MasterCard, Facebook and many others, the use of Big data for macroeconomic forecasting has started to be exploited. With respect to Official Statistics Big data could provide potentially important complementary information based on different information sets. Moreover, compared to economic indicators, Big data are timely available and, generally, not subject to any revision process. Between different Big data possible sources, data on payment instruments (cheques, credit transfers, direct debits, payment cards) represent a relevant source of information for short-term forecasting of the main macroeconomic variables.

Concerning consumption, they capture a wide range of spending activities and are available on a very timely basis. One of the issue of Big data anyway is to structure them in a statistical form. To reach this aim data needs to be controlled for outliers and then seasonally adjusted. The ability of retail payment data to forecast the short-term development of household consumption (both for durable and non-durable goods) has been tested compared to traditional benchmark.

Keywords: Big Data; Householed Consumption 